\title{
Assessment of renal parenchymal changes using isotope renography for genitourinary indications in pediatric age group-a study of 47 cases
}

\author{
Sunilkumar MN ${ }^{1}$, Gayathrivarma $N^{2}$, Parvathy V.K ${ }^{3}$ \\ ${ }^{1}$ Dr Menon Narayanankutty Sunilkumar, ${ }^{2}$ Dr Narendran Gayathrivarma, ${ }^{3}$ Dr Vadakut Krishnan Parvathy, Department of \\ Pediatrics, Amala Institute of Medical Sciences, Amala Nagar, Thrissur, Kerala, India,
}

Address for Correspondence: Dr. Sunilkumar MN, Assistant Professor, Department of Pediatrics, Amala Institute of Medical Sciences, Amala Nagar, Thrissur, Kerala, India, E-mail: sunilsree99@ yahoo.co.in

\begin{abstract}
Background: With the introduction of isotope renography using DMSA (Dimercaptosuccinic acid), more stress than ever has been put on the evaluation of renal parenchyma in a morphologically normal but injured kidney. Objective: To study the pattern of renal dysfunction and anomalies noted after isotope renography using DMSA. Materials and methods: A retrospective study was conducted at department of Paediatrics of Amala Institute of Medical Sciences, Thrissur after evaluating the hospital records involving children undergoing isotope renography using DMSA (IRDMSA) for genitourinary indications between August 1st 2012 and August $1^{\text {st }}$ 2013. Results: The common indications for IRDMSA were found to be urinary tract infections (UTI) (61.7\%), multicystic dysplastic kidneys (MCDK) (12.7\%), posterior urethral valve (PUV) (6.3\%) and unilateral hydronephrosis (6.3\%). Among the UTI group, 10.7\% had the evidence of bilateral renal scarring and $42.8 \%$ unilateral renal scarring. Only $32.1 \%$ had bilaterally normal kidneys. Analysis of 7 cases with significantly reduced differential function (DF $<30 / 70)$ showed associated vesicoureteral reflux (VUR) in $100 \%$ cases. A male predominance was noticed even though only one case had posterior urethral valve. Right kidney was found to be more susceptible than the left. A study of the scar topography showed majority to be localized to the upper pole and superolateral border. $100 \%$ of the MCDKs were found to be non-functional and was not visualized in the renogram. Conclusion: IRDMSA is a reliable imaging modality in the follow up of acute pyelonephritis in children, detecting structural abnormalities and also for identifying kidneys in children at risk for subsequent renal scarring.
\end{abstract}

Key words: DMSA, Renal scar, Differential function, Vesicoureteral reflux, Urinary tract infection

\section{Introduction}

Paediatricians in their routine practise encounter children of different age groups with urinary tract infections (UTI) and other conditions predisposing to UTI. These children may have associated anomalies of the genitourinary tract. The acute pyelonephritis (APN) are often detected by clinical manifestations and by routine laboratory findings. The role of imaging in patients with urogenital tract anomalies and subsequent UTI or APN is well known [1]. Literature review has revealed that the importance of early imaging without delay can help the treating paediatrician to administer prophylaxis for UTI or even refer the patient to a paediatric surgeon/urologist early without delay and compromising the kidney function [2]. An early identification of these anomalies and renal dysfunction can alleviate parental anxiety and also improve the

Manuscript received: $15^{\text {th }}$ March 2016

Reviewed: $28^{\text {th }}$ March 2016

Author Corrected; $10^{\text {th }}$ April 2016

Accepted for Publication: $20^{\text {th }}$ April 2016 prognosis of the recovery as the integrity of the genitourinary system is important for lessening the morbidity and mortality. And here is the role of imaging. Imaging could be one which delivers some amount of radiation such as the IRDMSA or the simple ultrasound Doppler scan (USD) free of radiation [3]. Many studies have been conducted to understand the priority of one investigation over other but IRDMSA has an important place in the diagnosis and follow up of these patients [4].

\section{Materials and Methods}

The medical college is a tertiary level referring centre and receives patients from nearby four districts. The nuclear medicine department has state of the art facilities and utilizes radio-isotopes in the diagnosis and treatment of diseases.. A retrospective study was conducted at the department of Paediatrics of Amala 
Institute of Medical Sciences, Thrissur after evaluating the hospital records involving children undergoing IRDMSA for genitourinary indications between August 1st 2012 and August $1^{\text {st }}$ 2013. All the 47 patients that underwent IRDMSA using technetium 99mTcdimercaptosuccinic acid (99mTc-DMSA) imaging sessions during this period were analysed. Inclusion criteria of the study took into consideration IRDMSA done for those babies and children with definite history of UTI, who were also under follow up after an episode of UTI and those on prophylaxis with antibiotics having an underlying renal anomaly as a cause of the UTI/APN. All children above the age of 18 were excluded. Profile of paediatric population in whom the IRDMSA was done was analysed based on gender , age, the various etiological causes of renal disease and dysfunction, the differential function of the kidneys, incidence of renal scarring, genetic syndromes in association with renal dysfunction and the topographic area of scarring in the kidney were given due importance. The study design was approved by Institutional Ethics Research Committee.

\section{Results}

During the study period a total number of 47 patients underwent IRDMSA in the department of Nuclear Medicine of the medical college. Among the children majority, 13(27.7\%) of these were between 1 to 2 years of age. Male children were $61.7 \%$ and females $38.3 \%$.

As regard with the etiological factors involved, the common indications for IRDMSA were found to be urinary tract infections (UTI) 29 (61.7\%), multicystic dysplastic kidneys (MCDK) 6 (12.7\%), posterior urethral valve 3 (PUV) (6.3\%) and unilateral hydronephrosis 3(6.3\%). Two children had ectopic kidneys. One each had solitary left kidney and in one child right kidney was not visualized. One child had the Prune belly syndrome (PBS) and one child had right megaureter (Table 1). In 29 children IRDMSA was done for UTI. In the UTI group majority were males19 (65.5\%). 6 children had recurrent UTI (20.8\%).11 children had febrile UTI and remaining with UTI had varying degrees of vesicoureteral reflux. Among the UTI group, $10.7 \%$ had the evidence of bilateral renal scarring and $42.8 \%$ had unilateral renal scarring. Only $32.1 \%$ had bilaterally normal kidneys. $25 \%$ had severe derangement of renal parenchymal function and $10.7 \%$ had enlarged kidneys (Table 2).

Table 1: Indication for IRDMSA.

\begin{tabular}{|c|l|l|l|}
\hline S. No & Age in years & Number (47) & \% \\
\hline 1. & UTI & 29 & $61.7 \%$ \\
\hline 2. & MCDK & 6 & $12.7 \%$ \\
\hline 3. & PUV & 3 & $6.3 \%$ \\
\hline 4. & $\begin{array}{l}\text { Unilateral } \\
\text { Hydronephrosis }\end{array}$ & 3 & $6.3 \%$ \\
\hline 5. & $\begin{array}{l}\text { Ectopic kidney/ } \\
\text { Solitary kidney/ } \\
\text { Non visualised kidney }\end{array}$ & 4 & $8.5 \%$ \\
\hline 6. & Prune Belly Syndrome & 1 & $2.1 \%$ \\
\hline 7. & Right megaureter & 1 & $2.1 \%$ \\
\hline
\end{tabular}

Table 2: Findings in UTI.

\begin{tabular}{|c|l|l|l|}
\hline S. No & Finding & Number & \% \\
\hline 1. & Unilateral renal scar & 12 & $42.8 \%$ \\
\hline 2. & Unilateral pyelonephritis & 7 & $25 \%$ \\
\hline 3. & Bilateral normal kidneys & 3 & $32.1 \%$ \\
\hline 4. & Bilateral renal scars & 3 & $10.7 \%$ \\
\hline 5. & Severe derangement of parenchymal function & 7 & $25 \%$ \\
\hline 6. & $\begin{array}{l}\text { Bilateral } \\
\text { pyelonephritis }\end{array}$ & 1 & $3.5 \%$ \\
\hline 7. & Enlarged kidneys & 3 & $10.7 \%$ \\
\hline
\end{tabular}


The differential function of the kidneys were also given due importance to understand the magnitude of the renal disease. Analysis of 7 cases with significantly reduced differential function (DF<30/70) showed associated VUR in $100 \%$ cases. A male predominance was noticed even though only one case had PUV. Right kidney was found to be more susceptible than the left in these 7 children. A study of the scar topography showed majority to be localized to the upper pole and superolateral border. The renal scars noted were also noted in the lower pole, inferomedial aspect of the kidneys (in 1 patient) and multiple scars were also seen in 1 patient. (Figure 1). 100\% of the MCDKs were found to be non-functional and were not visualized in the renogram.

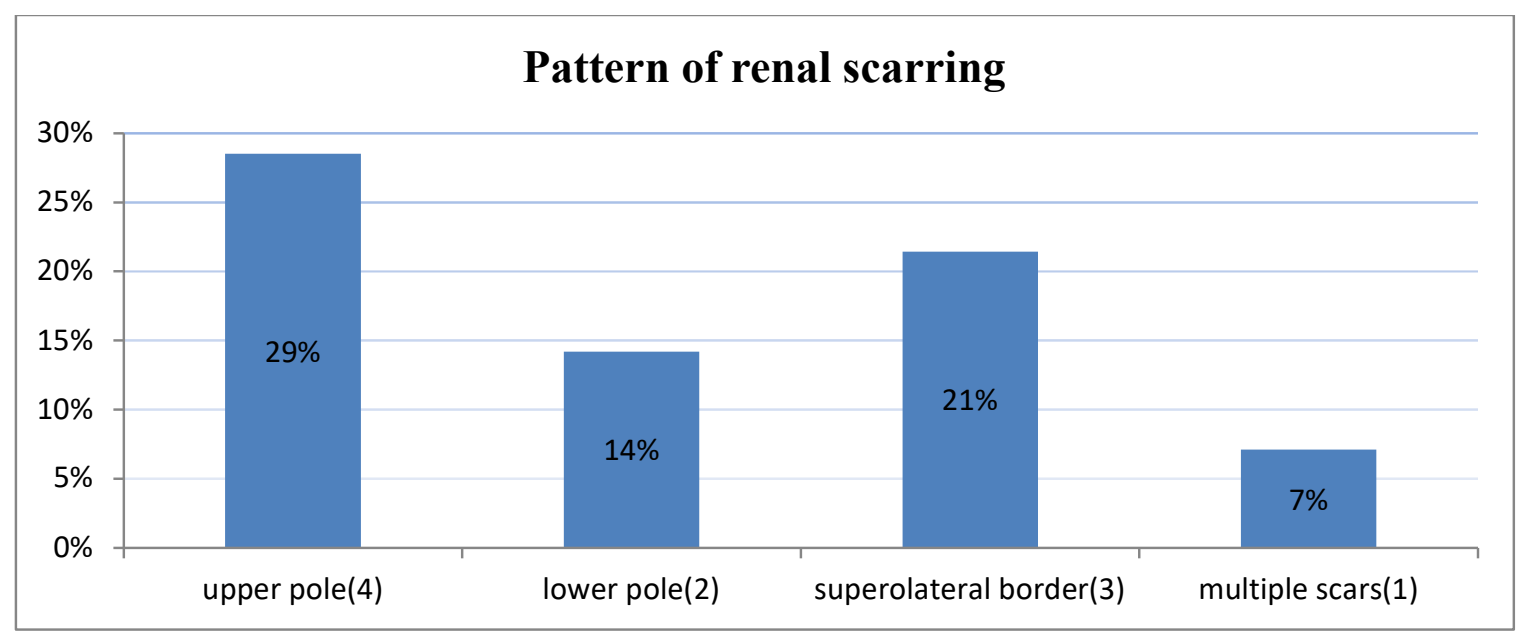

Figure 1: Pattern of renal scarring

\section{Discussion}

Radioimaging has revolutionised the management of common genitourinary infections and also to early diagnose any abnormalities in this system. The role of imaging in patients with urogenital tract anomalies and subsequent UTI and APN is well known [1].There was always developments in the field of radiology in the diagnosis of renal tract diseases especially for urinary tract infection (UTI). Intravenous pyelogram (IVP) in the past was the "gold standard" and only in about $25 \%$ of paediatric population with pyelonephritis IVP demonstrated abnormalities. IVP was replaced by the common USD to detect these abnormalities [2-5].With the development of nuclear medicine techniques using radio-isotopes, diseases could be identified early in their course, even before conventional imaging methods are able to detect the disease. The nuclear medicine department at the medical college has state of the art facilities and utilizes radio-isotopes in the diagnosis and treatment of diseases especially the renal disorders. Many studies have been conducted to understand the priority of one investigation over other but renal cortical scintigraphy with Technetium-99m glucoheptonate (99mTc GH) or $99 \mathrm{mTc}$ dimercaptosuccinic acid (99mTc DMSA) has an important place in the diagnosis and follow up of these patients[3, 4 ]. With the introduction of IRDMSA, more stress than ever has been put on the evaluation of renal parenchyma in a morphologically normal but injured kidney. The paediatric department takes care of the patients on an inpatient as well as outpatient basis .In this retrospective study 47 children who underwent $99 \mathrm{mTc}$ DMSA imaging sessions during the study period were analysed and 6 were inpatients and remaining outpatients. Similar studies have been conducted in different higher centers and pediatric population is a vulnerable group as evidenced by literature review [58].

Renal cortical scintigraphy with specific "radiotracer" 99mTc DMSA or $99 \mathrm{mTc}$ GH is the standard procedure in the initial evaluation of a child with UTI. This requires the injection of this radiotracer into the vein in the hand or elbow of the child under strict aseptic precautions. The tracer gets trapped by the cells of the kidney which has a tiny bit of radioactivity. The parents have a period of waiting time for the tracer to build up in the kidneys. A gamma camera then detects the DMSA radiotracer to obtain pictures of the kidneys and the procedure takes about $30-40$ minutes. The image reflects the kidney function, a cold spot on the picture is the topographical area where there is no radioactivity [ $2,5,9$ ]. After the scan, the $99 \mathrm{mTc}$ DMSA is excreted in 
the urine. The urine will be slightly radioactive, as a precaution, parents are recommended to wash their hands after changing the child's nappy, and dispose their nappies in a sealed plastic bag if it is a small child.

IRDMSA has been used as a modality for differentiating parenchymal involvement (APN) from nonparenchymal (lower UTI) involvement of the renal tract. As regard with the etiological factors involved, the common indications for IRDMSA were found to be UTI 29 (61.7\%), MCDK 6 (12.7\%), PUV (6.3\%) and unilateral hydronephrosis $3(6.3 \%)$. This is comparable to various clinical and experimental studies done in other studies $[9,10]$. Literature review has revealed an array of congenital anomalies of the kidney and urinary tract which ranges from mild, asymptomatic abnormalities to very severe, life-threatening pathologies. Many of these renal abnormalities could be part of a syndrome or sequence. Imaging modalities especially IRDMSA can be used to confirm and treat them judiciously without delay. In our study also two children had ectopic kidneys. One each had solitary left kidney and in one child right kidney was not visualized. One child had the PBS and one child had right megaureter (Table 1). So this can also help in modifying the natural history of these severe renal conditions. The knowledge of these anomalies and dysfunctions of the renal tract are pertinent in the expert diagnosis and management [11].

IRDMSA can localize the site of APN infection with a high degree of accuracy. Many recent studies have reported a sensitivity of $86 \%$ and specificity of $81 \%$ of pyelonephritis [10-13]. As APN is very common and renal scarring is associated with it the paediatrician should diagnose and treat it soon. A combination of laboratory findings such as urine routine to look for pus cells, urine culture and sensitivity and with typical clinical features, including flank pain, high-grade fever $\left(>38.5^{\circ} \mathrm{C}\right)$, and UTI help us to clinch the diagnosis of APN. In our study 29 children IRDMSA was done for UTI. In the UTI group majority were males19 (65.5\%). 6 children had recurrent UTI(20.8\%). 11 children had febrile UTI first episode and remaining with UTI had varying degrees of vesicoureteral reflux. This is in accordance with other studies [12,13]. Of the 12 children with VUR, 8 had grade I-II VUR and 4 had grade III-V VUR, 4 children were less than 2-years-old. Renal USD can be normal in the presence of APN. The sensitivity of USD for APN is low, in all age groups between $5-7 \%$. There lies the advantage of a DMSA scan in the early stages of UTI is to diagnose APN and start child on appropriate antibiotics. This helps to detect early the children at risk for renal damage and recurrent UTI/APN and thereby preventing future sequelae [11-13]. Improper treatment or severe APN can lead to renal scarring. Among the UTI group, $10.7 \%$ had the evidence of bilateral renal scarring and $42.8 \%$ had unilateral renal scarring. Only $32.1 \%$ had bilaterally normal kidneys. $25 \%$ had severe derangement of renal parenchymal function and $10.7 \%$ had enlarged kidneys (Table 2). In 2014 Sunilkumar et al from the department has reported atypical presentations of APN a rare case of xanthogranulomatous nephritis in a 2 month old female child and in our study also atypical congenital malformations were detected and analysed using IRDMSA[14 ].

The differential function of the kidneys were also given due importance to understand the magnitude of the renal disease. 99mTc DMSA is a well established static renal scanning agent that provides functional image of proximal renal tubular mass. A number of studies have shown that the relative uptake of $99 \mathrm{mTc}$ DMSA is a very good index of differential function and plasma flow $[15,16]$. Analysis of 7 cases with significantly reduced differential function $(\mathrm{DF}<30 / 70)$ showed associated VUR in $100 \%$ cases. A male predominance was noticed even though only one case had PUV. Right kidney was found to be more susceptible than the left in these 7 children. This are in accordance with other studies [ 4,13]. A study of the scar topography showed majority to be localized to the upper pole and superolateral border (Figure 1). Acquired renal scarring only occurs in sites corresponding to previous areas of APN as demonstrated by IRDMSA at the time of an UTI. Also renal scarring is independent of the presence or absence of VUR once the child has APN. The topography of scar localization is seen in other studies also $[2,4,9]$.

In the study $100 \%$ of the MCDKs were found to be non-functional and was not visualized in the renogram.MCDK is a congenital developmental anomaly where the the renal cortex is replaced by numerous cysts of multiple sizes.The dysplastic parenchyma of the kidneys anchors the cysts, and resembles a bunch of grapes. There is complete absence of the calyceal drainage system. The bilateral MCDK is life threatening and is fatal and MCDK is typically an unilateral disorder [18 ]. Nuclear renograms are used to evaluate the perfusion, function, and drainage of the 
kidneys, as there is uptake of the radiotracer into a functioning kidney and excretion into the renal pelvis, ureter, and bladder. MAG-3 (Tc-99m mercaptoacetyltriglycine, diethylenetriaminepentaacetic acid (DTPA), and DMSA are the preferred agents. In the scan in those areas of the MCDK, a photopenic region seen which represents displaced tissue with background activity only [17, 18 ]. A compensatory hypertrophy of the contralateral kidney was found in majority of children and lifelong nephrological care is recommended in these children with unilateral renal agenesis/MCDK due to higher risk of pathological changes in the single functioning kidney $[19,20]$.

The other etiologic causes for DMSA were child with solitary left kidney and in one child right kidney was not visualized. One child had the PBS and another had right megaureter. This is seen in other studies as well [ $21,22]$. The child with PBS was a 15 month old male child with impaired parenchymal function in both kidneys. PBS is a rare syndrome which can have association with other syndromes such as Down syndrome and is characterised by bilateral gross hydronephrosis, megaureter, and megacystis with abdominal muscle deficiency seen in males as in our study and other published reports [ 23].A urethral obstruction early in development of the fetus resulting in massive bladder distension and urinary ascites, which ultimately lead to degeneration of the abdominal wall musculature and failure of descent of testes occurs. The impaired elimination of urine from the bladder leads to its complications such as oligohydramnios, pulmonary hypoplasia, and Potter's facies and renal failure is the main cause of death in PBS $[23,24]$. The paediatrician faces lots of challenges in treating children with UTI and APN. But newer modalities in nuclear medicine such as IRDMSA can be used to diagnose and follow up these conditions.

\section{Conclusion}

Isotope renography using DMSA is a reliable imaging modality in the follow up of acute pyelonephritis in children, detecting structural abnormalities and also for identifying kidneys in children at risk for subsequent renal scarring .IRDMSA is also the isotope agent of choice for the detection of renal scarring. The knowledge of the renal tract infections, its anomalies and the modalities in nuclear medicine such as IRDMSA in its diagnosis is very crucial for all paediatric care providers.

\section{Acknowledgement}

The authors acknowledge the help of the MRD section of the medical college for their help and support. Also express gratitude to house surgeons, post graduate students,nursing staff, colleagues of Paediatric and Nuclear Medicine departments for their timely help and to Dr Ajith TA, Professor, Biochemistry, Amala Institute of Medical Sciences, Amala Nagar, Thrissur, Kerala, India during the preparation of the manuscript.

Source of Support: Nil

Conflict of Interest: None

Permission of IRB: Yes

\section{References}

1. Yoo JM, Koh JS, Han CH, Lee SL, Ha US, Kang SH, Jung YS, Lee YS. Diagnosing Acute Pyelonephritis with CT, Tc-DMSA SPECT, and Doppler Ultrasound: A Comparative Study. Korean J Urol. 2010 Apr;51(4):260-5. doi: 10.4111/kju.2010.51.4.260. Epub 2010 Apr 20.

2. Kawashima A, Sandler CM, Goldman SM. Imaging in acute renal infection. BJU Int. 2000 Jul;86 Suppl $1: 70-9$.

3. Meyrier A. [Diagnosis of acute pyelonephritis. Contribution of modern imaging]. Presse Med. 1991 Nov 9;20(36):1773-7.

4. Bhatnagar V, Mitra DK, Agarwala S, Kumar R, Patel C, Malhotra AK, Gupta AK. The role of DMSA scans in evaluation of the correlation between urinary tract infection, vesicoureteric reflux, and renal scarring. Pediatr Surg Int. 2002 Mar;18(2-3):128-34.

5. Conway JJ. The role of scintigraphy in urinary tract infection. Semin Nucl Med. 1988 Oct;18(4):308-19.

6. Sixt R, Stokland E. Assessment of infective urinary tract disorders. Q J Nucl Med. 1998 Jun;42(2):119-25.

7. Haycock GB. A practical approach to evaluating urinary tract infection in children. Pediatr Nephrol. 1991 Jul;5(4):401-2; discussion 403.

8. Smellie JM, Rigden SP, Prescod NP. Urinary tract infection: a comparison of four methods of investigation. Arch Dis Child. 1995 Mar;72(3):247-50.

9. Rushton HG, Majd M. Dimercaptosuccinic acid renal scintigraphy for the evaluation of pyelonephritis and scarring: a review of experimental and clinical studies. $\mathbf{J}$ Urol. 1992 Nov;148(5 Pt 2):1726-32. 
10. Guermazi F, Lenoir P, Verboven M, Smets A, Braeckman J, Jonckheer MH, Piepsz A. [Technetium 99m labeled dimercaptosuccinic acid (99m Tc-DMSA) scintigraphy in the diagnosis and follow-up of urinary infections in children]. Arch Fr Pediatr. 1993 May;50(5):391-8.

11. Rodriguez MM. Congenital Anomalies of the Kidney and the Urinary Tract (CAKUT). Fetal Pediatr Pathol. 2014 Oct-Dec;33(5-6):293-320. doi: 10.3109/15513815.2014.959678. Epub 2014 Oct 14.

12. Goldman M, Lahat E, Strauss S, Reisler G, Livne A, Gordin L, Aladjem M. Imaging after urinary tract infection in male neonates. Pediatrics. 2000 Jun;105(6):1232-5.

13. Lin $\mathrm{CH}$, Yang LY, Wamg HH, Chang JW, Shen MC, Tang RB. Evaluation of imaging studies for vesicoureteral reflux in infants with first urinary tract infection. Acta Paediatr Taiwan. 2007 MarApr;48(2):68-72.

14. Sunilkumar N M, Sasikumar, Gayathrivarma N, KrishnanParvathy V. Xanthogranulomatous Pyelonephritis in a 2 month Old Infant-Case Report. Pediatric Oncall July-September ,Art \#49. 2014 July 01;11:( 3) Art \#49,DOI: 10.7199/ped.oncall.2014.49.

15. Smokvina A, Grbac-Ivanković S, Girotto N, Dezulović MS, Saina G, Barković MM. The renal parenchyma evaluation: MAG3 vs. DMSA. Coll Antropol. 2005 Dec;29(2):649-54.

16. Gordon I, Evans K, Peters AM, Kelly J, Morales BN, Goldraich N, Yau A. The quantitation of 99TcmDMSA in paediatrics. Nucl Med Commun. 1987 Aug;8(8):661-70.

17. Sarhan OM, Alghanbar M, Alsulaihim A, Alharbi B, Alotay A, Nakshabandi Z. Multicystic dysplastic kidney: Impact of imaging modality selection on the initial management and prognosis. J Pediatr Urol. 2014 Aug;10(4):645-9,Epub 2014 Mar 29.

18. Hains D.S, Bates C.M, Ingraham.S, Schwaderer A.L,Management and etiology of the unilateral multicystic dysplastic kidney: a review Pediatr Nephrol. 2009 Feb;24(2):233-41. doi: 10.1007/s00467-008-0828-8. Epub 2008 May 15.

19. Singh JK, Kanojia RP, Narasimhan KL. Multicystic dysplastic kidney in children--a need for conservative and long term approach. Indian J Pediatr. 2009 Aug;76(8):809-12. doi: 10.1007/s12098-009-0117-y. Epub 2009 Apr 16.

20. Krzemień G, Roszkowska-Blaim M, Kostro I, Wojnar J, Karpińska M, Sekowska R. Urological anomalies in children with renal agenesis or multicystic dysplastic kidney. J Appl Genet. 2006;47(2):171-6.

21. de Lucas C, Nocea A, San RJ, Espínola B, Ecija JL, Vázquez Martul M. [Solitary kidney. Study of renal morphology and function in 95 children]. Nefrologia. 2006;26(1):56-63.

22. Sánchez Catalicio J, Gallego Peinado M, Pérez Angel F, Martinez Martínez MT, González Rodríguez JD, Contreras Gutiérrez JF.Megaureter detection through renal scintigraphy scan: Prune-Belly syndrome.. Rev Esp Med Nucl Imagen Mol. 2015 Dec 21. pii: S2253-654X(15)00166-3. doi: 10.1016/j.remn.2015.11.003.

23. Metwalley KA, Farghalley HS, Abd-Elsayed AA. Prune belly syndrome in an Egyptian infant with Down syndrome: a case report. J Med Case Rep. 2008 Oct 2;2:322. doi: 10.1186/1752-1947-2-322.

24. Seidel NE, Arlen AM, Smith EA, Kirsch AJ. Clinical manifestations and management of prune-belly syndrome in a large contemporary pediatric population. Urology. $2015 \quad$ Jan;85(1):211-5. doi: 10.1016/j.urology.2014.09.029. Epub 2014 Nov 8.

\section{How to cite this article?}

Sunilkumar MN, Gayathrivarma N, Parvathy V.K, Assessment of renal parenchymal changes using isotope renography for genitourinary indications in pediatric age group-a study of 47 cases:Int J Pediatr Res 2016;3(4):234239.doi:10.17511/ijpr.2016.i04.05. 